\title{
Diet and risk of diverticular disease in Oxford cohort of European Prospective Investigation into Cancer and Nutrition (EPIC): prospective study of British vegetarians and non-vegetarians
}

\author{
Francesca L Crowe nutritional epidemiologist, Paul N Appleby senior statistician, Naomi E Allen \\ epidemiologist, Timothy J Key professor of epidemiology
}

Cancer Epidemiology Unit, Nuffield Department of Clinical Medicine, University of Oxford, Oxford OX3 7LF, UK

\begin{abstract}
Objective To examine the associations of a vegetarian diet and dietary fibre intake with risk of diverticular disease.

Design Prospective cohort study.

Setting The EPIC-Oxford study, a cohort of mainly health conscious participants recruited from around the United Kingdom.

Participants 47033 men and women living in England or Scotland of whom 15459 (33\%) reported consuming a vegetarian diet.

Main outcome measures Diet group was assessed at baseline; intake of dietary fibre was estimated from a 130 item validated food frequency questionnaire. Cases of diverticular disease were identified through linkage with hospital records and death certificates. Hazard ratios and $95 \%$ confidence intervals for the risk of diverticular disease by diet group and fifths of intake of dietary fibre were estimated with multivariate Cox proportional hazards regression models.
\end{abstract}

Results After a mean follow-up time of 11.6 years, there were 812 cases of diverticular disease ( 806 admissions to hospital and six deaths). After adjustment for confounding variables, vegetarians had a $31 \%$ lower risk (relative risk $0.69,95 \%$ confidence interval 0.55 to 0.86 ) of diverticular disease compared with meat eaters. The cumulative probability of admission to hospital or death from diverticular disease between the ages of 50 and 70 for meat eaters was $4.4 \%$ compared with $3.0 \%$ for vegetarians. There was also an inverse association with dietary fibre intake; participants in the highest fifth ( $\geq 25.5 \mathrm{~g} /$ day for women and $\geq 26.1$ $\mathrm{g} /$ day for men) had a $41 \%$ lower risk $(0.59,0.46$ to $0.78 ; \mathrm{P}<0.001$ trend) compared with those in the lowest fifth ( $<14 \mathrm{~g} /$ day for both women and men). After mutual adjustment, both a vegetarian diet and a higher intake of fibre were significantly associated with a lower risk of diverticular disease.

Conclusions Consuming a vegetarian diet and a high intake of dietary fibre were both associated with a lower risk of admission to hospital or death from diverticular disease.

\section{Introduction}

Diverticular disease has been termed a "disease of western civilisation" because of its high prevalence in countries like the United Kingdom and United States compared with certain parts of Africa. ${ }^{1}$ In England, from 1989-90 to 1999-2000 the age standardised rates of admission to hospital for diverticular disease rose by $12 \%$ in men and $16 \%$ in women. ${ }^{2}$ Given the combination of a strong age related increase in the risk of the disease $^{3}$ and an ageing population, the burden of diverticular disease in the UK is expected to increase further.

Ever since Painter and Burkitt ${ }^{1}$ published their hypothesis that diverticular disease was a fibre deficiency disease caused by the refining of carbohydrate in the diet, a low fibre diet has been thought to be an important risk factor, ${ }^{4-6}$ despite there being little evidence from prospective cohort studies to substantiate this hypothesis. In the only such study (health professionals follow-up study), Aldoori et al reported an inverse association between dietary fibre intake and risk of symptomatic diverticular disease in men. ${ }^{7}$ Results from this study also suggested that other dietary factors - such as a high intake of meat - might increase the risk of developing diverticular disease, and the finding of lower rates of diverticular disease among vegetarians compared with meat eaters in a small cross sectional analysis ${ }^{8}$ lends support to this idea.

We examined the associations of vegetarianism and the intake of dietary fibre (defined as non-starch polysaccharides) with the risk of diverticular disease using information from hospital admission data and death certificates for England and Scotland in men and women taking part in the European Prospective Investigation into Cancer and Nutrition (EPIC)-Oxford cohort.

\section{Methods}

The EPIC-Oxford cohort was designed to recruit participants with a wide range of diets and targeted vegetarians and vegans 
as well as the UK general population. Between 1993 and 1999, 57446 men and women aged 20 and older completed the baseline questionnaire; a more detailed description of this study has been published elsewhere. ${ }^{9}$ Briefly, in the pilot phase of the study, women were recruited into the EPIC-Oxford study through general practices in Scotland. In the second general practice recruitment phase of the study, all men and women aged 35-69 on the lists of collaborating general practices in Oxfordshire, Buckinghamshire, and Greater Manchester were contacted and asked to participate. Consenting participants completed the questionnaire on diet and lifestyle and then attended an appointment at their general practitioners, where their questionnaires were checked and anthropometric measurements and a blood sample were collected. The second recruitment method was by post and recruited men and women living throughout the UK aged 20 and over, with a specific focus of targeting individuals with vegetarian and vegan diets. Questionnaires were mailed to all members of the Vegetarian Society of the UK, the Vegan Society, and all participants from the Oxford Vegetarian Study. ${ }^{10}$ Respondents to the questionnaire were also asked to pass on the names and addresses of family members and friends who might be interested in participating and a questionnaire was sent to them.

\section{Assessment of diet and lifestyle variables}

At recruitment, participants completed a questionnaire on lifestyle and diet that included a validated semiquantitative food frequency questionnaire, which estimated the intake of 130 different foods and beverages over the past year. ${ }^{112}$ To calculate the mean daily intakes of nutrients, the frequency of consumption of each food or beverage item was multiplied by a standard portion size and the nutrient content of the food or beverage. ${ }^{13-22}$ Participants were categorised into one of four diet groups based on their response to questions asking whether they ate any meat, fish, eggs, and dairy products. Participants were categorised as those who eat meat ("meat eaters"), those who do not eat meat but eat fish ("no meat but some fish"), those who do not eat meat or fish but eat dairy products and/or eggs ("vegetarians"), and those who do not eat meat, fish, eggs, or dairy products ("vegans"). For the women recruited in Scotland during the pilot phase of the study, and the first 1300 men and women recruited through the general practices, these dietary categorisation questions were not asked, and diet group was assigned according to their responses to questions on the intake of meat, fish, dairy products, and eggs provided in the food frequency questionnaire.

In the main questionnaire, participants were asked to report their height and weight, and these measurements were also taken in a subgroup of participants recruited through general practitioners $(n=4808)$; the correlation between the self reported and measured height and weight was $r>0.9 .{ }^{23}$ Measured or self reported height and weight were used to calculate body mass index (BMI; weight $(\mathrm{kg}) /$ height $\left(\mathrm{m}^{2}\right)$ ), which was divided into five categories: $<20.0,20.0-22.4,22.5-24.9,25.0-27.4$, and $\geq 27.5$. The questionnaire also asked about the use of tobacco products, and a smoking variable was created and categorised as "never smoker," "former smoker," "current light smoker" $(<15$ cigarettes/day), or "current heavy smoker" ( $\geq 15$ cigarettes/day). Alcohol consumption estimated from the food frequency questionnaire was categorised as $<1,1-7,8-15$, and $\geq 16 \mathrm{~g} /$ day. Participants were asked to report the age at which they left school and the qualifications obtained and were categorised as having "some secondary school," "higher secondary school," or "university degree or equivalent." The Townsend deprivation index,${ }^{24}$ based on the location of residence at recruitment (postcode), was used to categorise participants into quarters of socioeconomic status. Participants were asked about time spent participating in activities such as walking, cycling, and other physical exercise, and these were combined and categorised as "inactive" or "active." Women were asked about their current and past use of oral contraceptives and hormone replacement therapy and were categorised as "ever users" or "never users" in each case. Participants were asked to report if they had had a diagnosis of a range of conditions including diabetes, hypertension, and hyperlipidaemia or whether they were taking medication for any long term illness or condition; each such variable being categorised as "yes" or "no." An "unknown" category was added for each variable where data were missing or incomplete.

Participants were excluded from the analysis if they were older than 90 at recruitment $(\mathrm{n}=56)$, had no follow-up information $(n=711)$, had a self reported $(n=612)$ or registered $(n=1370)$ malignant cancer at baseline, had missing information on smoking $(n=295)$ or diet group $(n=239)$, or had unreliable data on nutrient intake $(\mathrm{n}=1128)$, or if they reported altering their diet because of bowel problems (such as irritable bowel or diverticulitis) in the baseline questionnaire $(n=3756)$, leaving a total of 49279 participants.

Cases of diverticular disease were ascertained by linking each participant's National Health Service (NHS) number-a unique personal identifier of NHS records-and other personal information such as date of birth to computerised records of NHS hospital admissions, procedures, and operations from the Information Services Division of Scottish Morbidity Records $(\mathrm{SMR})^{25}$ and from Hospital Episode Statistics (HES) ${ }^{26}$ in England. There was no information on hospital admission for 2241 participants whose nation of residence was not England or Scotland (that is, Northern Ireland or Wales), leaving 47038 participants for whom information was available from 1 January 1981 to 31 December 2008 for SMR and 1 April 1997 to 31 March 2009 for HES. Five participants were excluded from the analysis because the date of diagnosis of diverticular disease occurred before the date of recruitment, leaving 47033 participants available for analysis. Participants were followed up for cause of death until 30 September 2009 by record linkage with the UK NHS central register. The diagnostic codes used on SMR and HES records or on the death certificates were coded by those agencies using the four digit code from the WHO International Classification of Diseases (ICD) 9th or, from 1 April 1996, 10th revisions, for diseases and medical conditions. The SMR records store up to six diagnoses and the HES Data Warehouse stores up to seven diagnoses from April 1997 to April 2002, 14 diagnoses from April 2002 to April 2007, and thereafter up to 20 diagnoses.

\section{Statistical analysis}

The main outcome was diverticular disease (ICD-9 562 and ICD-10 K57, which includes diverticulitis, diverticulosis, and diverticulum of the large or small intestine) defined as the earliest such diagnosis from HES or SMR data or listing as a cause of death on the death certificate. Person years were calculated from recruitment until the date of first hospital diagnosis of diverticular disease or death with mention of diverticular disease, other death, emigration, age 90 , or other loss to follow-up or the last available date of SMR records (31 December 2008) for participants living in Scotland or of HES records (31 March 2009) for participants living in England, whichever occurred first. The exception was for participants living in England whose date of recruitment preceded 1 April 
1997 (earliest date of hospital admissions data for England) for whom the beginning of follow-up was set to 1 April 1997.

We used Cox proportional hazards regression to calculate hazard ratios as estimates of the relative risks for diverticular disease and $95 \%$ confidence intervals, using age as the underlying time variable. The intake of dietary fibre (Englyst; non-starch polysaccharides) was divided into sex specific fifths based on the distribution of intake in the whole cohort. All analyses are stratified by sex, method of recruitment (general practitioner or postal), and region of residence and adjusted for smoking, education level, Townsend deprivation index, self reported hyperlipidaemia, receipt of long term treatment for any illness, use of oral contraceptives, use of hormone replacement therapy, BMI, and, for the analyses of dietary fibre intake and risk, sex specific fifths of energy intake. We assessed the association between diet group and risk of diverticular disease with various categorisations and also according to the duration of adherence to a vegetarian diet (non-vegetarian, vegetarian for five years or less or of unknown duration, vegetarian for more than five years). We assessed the difference in the risk of diverticular disease for categorical variables with a $\chi^{2}$ test and tested for trend by replacing the fifths of dietary fibre by a continuous variable equal to the sex specific median in each fifth.

In a sensitivity analysis, we assessed the associations of diet group and dietary fibre with risk of diverticular disease after excluding the first two years of follow-up and examined the association between dietary fibre and risk of diverticular disease among meat eaters only. We also examined the main effects of diet group and intake of dietary fibre using an end point for which diverticular disease was the primary hospital diagnosis or the underlying cause of death. Heterogeneity in the association between diet group and intake of dietary fibre with the relative risk of diverticular disease by each of sex and age $(<60$ and $\geq 60)$ was assessed by adding appropriate interaction terms to the regression models and testing for significance with a likelihood ratio test.

All statistical analyses were performed with Stata statistical software, release 10 (StataCorp, College Station, TX). Two sided $\mathrm{P}$ values $<0.05$ were considered significant.

\section{Results}

After a follow-up time of 547312 person years (mean 11.6 years), there were 812 cases of diverticular disease (806 of these were from hospital admissions data and six from causes of death). In most cases ( $>95 \%)$ the diagnosis was "diverticular disease without perforation or abscess" either of the large intestine $(n=560,69.0 \%)$ or the part of the intestine was not specified $(n=221,27.2 \%)$.

Tables 1 and 2 show the characteristics of the 47033 participants by sex for non-vegetarians and vegetarians. Of all the participants, $76 \%$ were women, and $35 \%$ of men and $32 \%$ of women reported consuming a vegetarian diet. Among both men and women, vegetarians were younger than non-vegetarians; about $80 \%$ of the vegetarian men and women were younger than 50 at recruitment compared with around $50 \%$ of the non-vegetarian men and $60 \%$ of the non-vegetarian women. There was a low prevalence of smoking, ranging from $10 \%$ of vegetarian women to $15 \%$ of non-vegetarian men. Both the median intake of alcohol and the median BMI were highest among the non-vegetarian men and lowest among the vegetarian women. The proportion of non-vegetarians who reported a previous diagnosis of diabetes, hypertension, or hyperlipidaemia was about two to three times higher than among the vegetarians. Over $25 \%$ of non-vegetarians reported receiving some type of long term medical treatment at recruitment compared with less than $20 \%$ of vegetarians. The proportion who reported current or previous use of oral contraceptives was slightly higher among vegetarian women, whereas the use of hormone replacement therapy was almost three times higher among non-vegetarian women.

About two thirds of the vegetarians had been adhering to their diets for more than five years at the time of recruitment, and in the first follow-up questionnaire mailed about five years later, $90 \%$ of male and $84 \%$ of female vegetarians reported that they were still consuming a vegetarian diet (table 2). Among non-vegetarians, the median intake of meat was higher in men than women. Women had a higher intake of fruits and vegetables than men, and vegetarians consumed slightly more fruit and vegetables than non-vegetarians. Among the non-vegetarians, the median intake of dietary fibre (18 g/day for both men and women) was lower than in vegetarians ( $22 \mathrm{~g} /$ day and $21 \mathrm{~g} /$ day for men and women, respectively).

Compared with non-smokers, there was a $31 \%$ higher risk of diverticular disease among former smokers and a $34 \%$ and $86 \%$ higher risk for light ( $<15$ cigarettes/day) and heavy $(\geq 15$ cigarettes/day) smokers, respectively (table 3 ). After adjustment for smoking, there was no significant association between the consumption of alcohol and risk of diverticular disease. There was a significant positive relation between BMI and risk of diverticular disease; compared with those with a BMI of 20.0-22.5, the risk was $37 \%$ lower among participants with a BMI $<20$ and $67 \%$ higher among participants with a BMI $\geq 27.5$. The risk for diverticular disease was lower in participants with higher than with lower educational attainment, and risk was higher also in those with low rather than with high socioeconomic status. Participants who reported having hypertension or hyperlipidaemia had a $44 \%$ or $47 \%$ greater risk of developing diverticular disease, respectively, compared with those who did not report having the condition. There was also a significantly greater risk of diverticular disease among participants who reported receiving long term medical treatment and among women who had used oral contraceptives or hormone replacement therapy.

Results in table 4 show that after adjustment for a range of confounding variables including BMI, vegetarians (vegetarian or vegan) had a $30 \%$ lower risk of developing diverticular disease than non-vegetarians (those who eat meat or fish, or both). In analyses that subdivided the non-vegetarian group, those who do not eat meat but eat some fish did not have a significantly lower risk of developing diverticular disease than meat eaters (relative risk $0.91,95 \%$ confidence interval 0.71 to 1.16); however, risk of diverticular disease was $31 \%$ lower among vegetarians or vegans $(0.69,0.55$ to 0.86$)$. In analyses that separated vegans from vegetarians, there was an even lower risk among the vegans (four cases); compared with meat eaters the risk of diverticular disease was 0.28 (0.10 to 0.74 ).

Using the absolute rates of admission to hospital or death from diverticular disease, the cumulative probability of diverticular disease between ages 50 and 70 for meat eaters was $4.4 \%$ and the cumulative probability in vegetarians or vegans was $3.0 \%$. Vegetarians and vegans also had a significantly lower risk of diverticular disease than meat eaters after adjustment for sex specific fifths of dietary fibre intake (relative risk 0.79 ( 0.63 to $1.00)$ and 0.32 (0.12 to 0.87 ), respectively). There was no evidence that the association between vegetarianism and diverticular disease differed according to duration of adherence to a vegetarian diet. In the fully adjusted model, the risk among vegetarians who had followed a vegetarian diet for more than 
five years was 0.72 ( 0.57 to 0.92 ) and for all other vegetarians the relative risk was 0.64 ( 0.42 to 0.97 ) compared with non-vegetarians.

In the fully adjusted model the association between the quantity of meat consumed and risk of diverticular disease was not significant (table 5); compared with those with the highest intake of meat ( $\geq 100 \mathrm{~g} /$ day), the risk of diverticular disease for those with an intake less than $50 \mathrm{~g}$ /day was 0.95 (0.76 to 1.18 ). There was, however, a significant inverse dose-response relation between the intake of dietary fibre and risk of diverticular disease. Participants in the highest fifth of dietary fibre $(\geq 25.5$ $\mathrm{g} /$ day for women and $\geq 26.1 \mathrm{~g} /$ day for men) had a $42 \%$ lower risk (relative risk $0.58,0.46$ to 0.73 ) compared with participants with the lowest intake of fibre $(<14 \mathrm{~g} /$ day for both women and men). Adjustment for confounding variables made little difference to this association. After further adjustment for diet group, the association was slightly attenuated but remained significant ( $0.66,0.50$ to $0.86 ; \mathrm{P}=0.002$ for trend). There was also a significant inverse association between the intake of dietary fibre and risk of diverticular disease among meat eaters only; compared with meat eaters in the lowest fifth of dietary fibre intake, those in the highest fifth had a $26 \%$ lower risk of developing diverticular disease $(0.74,0.54$ to $1.00 ; \mathrm{P}=0.018$ for trend).

There was no evidence of heterogeneity in the association between diet group or fibre intake and risk of diverticular disease between men and women (table 6) or between older and younger participants (table 7). In a sensitivity analysis that excluded the first two years of follow-up (752 cases of diverticular disease included), the associations of diet group and dietary fibre with risk of diverticular disease remained significant; the relative risk for vegetarians or vegans compared with meat eaters was $0.72(0.57$ to 0.90$)$ and the risk for the highest versus the lowest fifth of dietary fibre intake was 0.62 ( 0.47 to $0.82 ; \mathrm{P}<0.001$ for trend). In analyses where cases were restricted to participants for whom diverticular disease was the primary diagnosis or underlying cause of death $(\mathrm{n}=531$ cases included), the relative risk for vegetarians or vegans versus meat eaters was $0.72(0.55$ to 0.95 ), and the risk for the highest versus the lowest fifth of dietary fibre intake was 0.61 ( 0.44 to $0.84 ; \mathrm{P}=0.002$ for trend).

\section{Discussion}

\section{Findings in relation to other studies}

In this prospective cohort study of generally health conscious British adults, a vegetarian diet and a relatively high intake of dietary fibre ( $>25 \mathrm{~g} /$ day) were both associated with a reduced risk of being admitted to hospital with or dying from diverticular disease. Vegans had an even lower risk of diverticular disease but this was based on small numbers. These results are consistent with the previous findings of a cross sectional study that showed a lower prevalence of asymptomatic diverticular disease among vegetarians than non-vegetarians. ${ }^{8} \mathrm{~A}$ further analysis of that study population and the EPIC-Oxford cohort suggested that both a vegetarian diet and a high intake of dietary fibre were correlated with rapid bowel transit times ${ }^{27}$ and increased frequency of bowel movements, ${ }^{28}$ which could be the biological mechanism through which a vegetarian diet and a high intake of dietary fibre lowers the risk of diverticular disease. A reduced transit time means that less water is reabsorbed from the lower gastrointestinal tract resulting in larger softer stools that are easier to pass; this in turn could lead to a lower intraluminal pressure and a reduced likelihood of forming the pouches or bulges through the weakened intestinal wall that are characteristic of diverticula. ${ }^{6}$ This finding of a possible protective effect of vegetarianism, regardless of the time of adherence to the diet, suggests that even in the short term, a vegetarian diet could be associated with a lower risk of diverticular disease, although this should be confirmed in other prospective studies. Our finding of a lower risk of diverticular disease among men and women with a higher fibre intake is consistent with results from the health professionals follow-up study of 385 cases of symptomatic diverticular disease among 47888 men. ${ }^{7}$ The association between foods that are a source of dietary fibre and risk of diverticular disease has also been investigated in other observational studies, but results have been inconsistent. In a case-control study conducted in Greece, Manousos et al reported a significant inverse association btween the intake of vegetables, cereals (in particular brown bread), and starchy roots and the risk of symptomatic diverticular disease (100 cases). ${ }^{29} \mathrm{~A}$ Taiwanese case-control study, however, found no significant association between the intake of fruits and vegetables and asymptomatic diverticular disease ( 86 cases) ${ }^{30}$ Similarly, a recent prospective study of patients undergoing colonoscopy in South Korea found no significant difference in the consumption of vegetables, fermented vegetables (kimchi), fruits, and fruit juices between participants who received a diagnosis of diverticular disease (103 cases) compared with those who did not. ${ }^{31}$ While fruits and vegetables are sources of fibre, assessing the intake of these foods alone might not adequately categorise participants according to their intake of fibre and, because of their small sample sizes, these studies are unlikely to have the power to detect small or moderate associations with the risk of diverticular disease. Moreover, both these study populations were from Asia where all $^{30}$ or most $^{31}$ cases of diverticular disease affected the right side of the colon and are thought to have a different pathophysiology from left sided diverticular disease, ${ }^{32}$ which is more common among Western populations.

A higher intake of meat might be related to a greater risk of diverticular disease by altering the metabolism of bacteria in the colon, ${ }^{33}$ which could lead to a weakening of the colon wall ${ }^{34}$ thus increasing the risk of developing diverticular disease. There is evidence from two small case-control studies of a positive association between meat intake and diverticular disease, ${ }^{29} 30$ and there was a greater risk of diverticular disease among men consuming larger amounts of red meat in the health professionals follow-up study. ${ }^{7}$ Despite the finding of a lower incidence of diverticular disease among vegetarians compared with meat eaters, our results showed no significant association between the amount of meat consumed and the incidence of diverticular disease among meat eaters. It could be that the intake of meat in this study population was too low to influence the risk of disease or the range was too narrow to detect a significant association; however, if meat is an important risk factor for diverticular disease then it is surprising that the risk was not significantly lower among participants who ate some fish but no meat.

\section{Strengths and limitations}

The strengths of this study include the prospective design, the large number of incident cases of diverticular disease and the wide range in the intake of dietary fibre. Moreover, 33\% (15 459) of these participants reported consuming a vegetarian diet, with most maintaining a vegetarian diet five years later, which allows for a reliable estimation of the association between vegetarianism and diverticular disease. The associations between diet group and intake of dietary fibre and risk of diverticular disease were significant after we excluded participants diagnosed with diverticular disease in the first two years of follow-up, reducing the possibility of reverse causality. 
The absolute rates of diverticular disease in the general British population might differ from that of $4.4 \%$ among meat eaters aged 50-70 given that this was not a representative sample. Cases of diverticular disease were identified by record linkage with information from hospital admissions records for England and Scotland and so the incidence rates reported are likely to underestimate the true incidence of diverticular disease in this study population. If there was a tendency for vegetarians to undergo fewer investigative techniques such as colonoscopy or barium enema, forgo admission to hospital for diverticular disease, or be treated in non-NHS hospitals (which would not be captured with HES and SMR), then this might bias the association between diet group and risk of diverticular disease towards a lower risk for vegetarians. Meat eaters or participants with a lower intake of dietary fibre might experience more colonic symptoms (such as abdominal pain, diarrhoea, or constipation), which could increase the likelihood of having an examination and being diagnosed with diverticular disease. There is, however, no clear consensus as to whether the presence of colonic symptoms increases the likelihood of diverticular disease being discovered or whether uncomplicated diverticular disease is the cause of colonic symptoms. ${ }^{35}$ The validity of a diagnosis of diverticular disease from hospital records has not yet been investigated; however, it is unlikely that there would be a differential bias in the accuracy of a diagnosis according to diet group or dietary fibre intake.

The finding of a lower incidence of diverticular disease among vegetarians in this study was not explained by a higher fibre intake or differences in other non-dietary variables (such as $\mathrm{BMI}$. Confounding by unmeasured variables might partially explain the lower risk of diverticular disease among vegetarians, although given that vegetarians had a $30 \%$ lower risk of diverticular disease any effect would have to be substantial. The inverse association between fibre intake and diverticular disease seems to have been partly driven by the higher intake of dietary fibre among vegetarians; however, the inverse association remained significant after adjustment for diet group, suggesting that dietary fibre intake has an independent effect on diverticular disease over and above a vegetarian diet. Moreover, there was an inverse association between dietary fibre intake and diverticular disease among meat eaters only.

Our results need to be re-examined in other large prospective studies. Further follow-up of this cohort might also clarify whether similar results for diet group and intake of dietary fibre are found for complicated diverticular disease (that is, diverticular disease with abscess, perforation, or fistula) of which there were too few cases in the current analysis to obtain reliable estimates of these associations. The inverse association between fibre and diverticular disease is strong and consistent with previous research and might be causal. The 2000-1 UK National Diet and Nutrition Survey showed that $72 \%$ of men and $87 \%$ of women were not meeting the recommended average intake for dietary fibre of $18 \mathrm{~g} / \mathrm{day},{ }^{36}$ and so the proportion of cases of diverticular diseases in the general population attributed to a low fibre diet could be considerable. These findings lend support to public health recommendations that encourage the consumption of foods high in fibre such as wholemeal breads, wholegrain (unrefined) cereals, fruits, and vegetables.

We thank all the participants in the EPIC-Oxford cohort for their invaluable contribution to the study, Anna Zawadzka for her help with obtaining permission to access data from hospital records in England and Scotland, and Neeraj Bhala for his valuable advice on this manuscript.
Contributors: FLC specified the analyses and wrote the manuscript. PNA performed the analyses and edited drafts of the manuscript. NEA specified analyses and edited drafts of the manuscript. TJK conceived the study, specified analyses, and edited drafts of the manuscript. All authors had full access to all of the data (including statistical reports and tables) in the study and can take responsibility for the integrity of the data and the accuracy of the data analysis. FLC and TJK are guarantors.

Funding: The EPIC-Oxford study was funded by Cancer Research UK (grant number: C570/A11691). The funders played no role in designing or conducting the study or in the collection, management, analysis, and interpretation of the data, nor did they have any input into the preparation, review, or approval of this manuscript.

Competing interests: All authors have completed the ICMJE uniform disclosure form at www.icmje.org/coi_disclosure.pdf (available on request from the corresponding author) and declare: no support from any organisation for the submitted work; no financial relationships with any organisations that might have an interest in the submitted work in the previous three years; TJK is a member of the Vegan Society, UK. Ethical approval: The EPIC-Oxford Study has been approved by the multicentre research ethics committee (MREC/02/0/90), and all study participants gave written informed consent to be included. The Information Centre for Health and Social Care in England and the Information and Statistics Division in Scotland gave approval for access and linkage to hospital records.

Data sharing: No additional data available.

1 Painter NS, Burkitt DP. Diverticular disease of the colon: a deficiency disease of Western civilization. BMJ 1971;2:450-4

2 Kang JY, Hoare J, Tinto A, Subramanian S, Ellis C, Majeed A, et al. Diverticular disease of the colon—on the rise: a study of hospital admissions in England between 1989/1990 and 1999/2000. Aliment Pharmacol Ther 2003:17:1189-95.

3 Jeyarajah S, Faiz O, Bottle A, Aylin P, Bjarnason I, Tekkis PP, et al. Diverticular disease hospital admissions are increasing, with poor outcomes in the elderly and emergency admissions. Aliment Pharmacol Ther 2009;30:1171-82.

4 Korzenik JR. Case closed? Diverticulitis: epidemiology and fiber. J Clin Gastroenterol 2006;40(suppl 3):S112-6.

5 Martel J, Raskin JB. History, incidence, and epidemiology of diverticulosis. J Clin Gastroenterol 2008:42:1125-7.

6 Stollman N, Raskin JB. Diverticular disease of the colon. Lancet 2004;363:631-9.

7 Aldoori WH, Giovannucci EL, Rimm EB, Wing AL, Trichopoulos DV, Willett WC. A prospective study of diet and the risk of symptomatic diverticular disease in men. $\mathrm{Am} \mathrm{J}$ Clin Nutr 1994;60:757-64.

8 Gear JSS, Ware A, Fursdon P, Mann JI, Nolan DJ, Brodribb AJM, et al. Symptomless diverticular disease and intake of dietary fibre. Lancet 1979;1:511-4.

9 Davey GK, Spencer EA, Appleby PN, Allen NE, Knox KH, Key TJ. EPIC-Oxford: lifestyle characteristics and nutrient intakes in a cohort of 33883 meat-eaters and 31546 non meat-eaters in the UK. Public Health Nutr 2003;6:259-68.

10 Appleby PN, Thorogood M, Mann JI, Key TJA. The Oxford vegetarian study: an overview. Am J Clin Nutr 1999;70(suppl 3):525-31S.

11 Bingham SA, Gill C, Welch A, Day K, Cassidy A, Khaw KT, et al. Comparison of dietary assessment methods in nutritional epidemiology: weighed records $v 24 \mathrm{~h}$ recalls, food-frequency questionnaires and estimated-diet records. Br J Nutr 1994;72:619-43.

12 Bingham SA, Cassidy A, Cole TJ, Welch A, Runswick SA, Black AE, et al. Validation of weighed records and other methods of dietary assessment using the 24h urine nitrogen technique and other biological markers. Br J Nutr 1995;73:531-50.

13 Holland B, Welch A, Unwin I, Buss D, Paul A, Southgate D. McCance and Widdowson's the composition of foods.5th ed.Royal Society of Chemistry, 1991.

14 Chan W, Brown J, Buss D. Miscellaneous foods. 4th supplement to McCance and Widdowson's The composition of foods.5th ed.Royal Society of Chemistry, 1994.

15 Chan W, Brown J, Lee S, Buss D. Meat, poultry and game. 5th supplement to McCance and Widdowson's the composition of foods.5th ed.Royal Society of Chemistry, 1995.

16 Chan W, Brown J, Church S, Buss D. Meat products and dishes. 6th supplement to McCance and Widdowson's the composition of foods.5th ed. Royal Society of Chemistry, 1996.

17 Holland B, Unwin I, Buss D. Cereals and cereal products. 3rd supplement to McCance and Widdowson's the composition of foods. 4th ed.Royal Society of Chemistry, 1988.

18 Holland B, Unwin I, Buss D. Milk products and eggs. 4th supplement to McCance and Widdowson's the composition of foods. 4th ed.Royal Society of Chemistry, 1989.

19 Holland B, Unwin I, Buss D. Vegetables, herbs and spices. 5th supplement to McCance and Widdowson's the composition of foods.4th ed.Royal Society of Chemistry, 1991.

20 Holland B, Unwin I, Buss D. Fruit and nuts. 1st supplement to McCance and Widdowson's the composition of foods.5th ed.Royal Society of Chemistry, 1992.

21 Holland B, Welch A, Buss D. Vegetable dishes. 2nd supplement to McCance and Widdowson's the composition of foods. 5th ed. Royal Society of Chemistry, 1992.

22 Holland B, Brown J, Buss D. Fish and fish products. 3rd supplement to McCance and Widdowson's the composition of foods. 5th ed.Royal Society of Chemistry, 1993

23 Spencer EA, Appleby PN, Davey GK, Key TJ. Validity of self-reported height and weight in 4808 EPIC-Oxford participants. Public Health Nutr 2002;5:561-5.

24 Townsend $\mathrm{P}$, Phillimore $\mathrm{P}$, Beattie $\mathrm{A}$. Health and deprivation: inequality and the north.Croom Helm, 1988. 


\section{What is already known on this topic}

Low fibre diet is thought to be an important risk factor for diverticular disease, but this has been based on results from a single prospective study

Vegetarians might have a lower risk of diverticular disease, but this has not been examined before in a prospective study

\section{What this study adds}

Results from this prospective study suggest that consuming a vegetarian diet and a high intake of dietary fibre are both associated with a reduction in the risk of diverticular disease

25 Information and Services Division Scotland. Latest statistics. 2011. www.isdscotland.org/ isd $/ 1 . \mathrm{html}$.

26 HESonline Hospital episodes statistics. 2011. www.hesonline.nhs.uk.

27 Gear JSS, Brodribb AJM, Ware A, Mann JI. Fibre and bowel transit times. Br J Nutr 1981;45:77-82.

28 Sanjoaquin MA, Appleby PN, Spencer EA, Key TJ. Nutrition and lifestyle in relation to bowel movement frequency: a cross-sectional study of 20630 men and women in EPIC-Oxford. Public Health Nutr 2004;7:77-83.

29 Manousos O, Day NE, Tzonou A. Diet and other factors in the aetiology of diverticulosis: an epidemiological study in Greece. Gut 1985;26:544-9.

30 Lin OS, Soon M, Wu S, Chen Y, Hwang K, Triadafilopoulos G. Dietary habits and right-sided colonic diverticulosis . Dis Colon Rectum 2000;43:1412-8.

31 Song JH, Kim YS, Lee JH, Ok KS, Ryu SH, Lee JH, et al. Clinical characteristics of colonic diverticulosis in Korea: a prospective study. Korean J Intern Med 2010;25:140-6.
32 Ryan P. Changing concepts in diverticular disease. Dis Colon Rectum 1983;26:12-8.

33 Cummings $\mathrm{JH}$, Hill MJ, Bone ES. The effect of meat protein and dietary fiber on colonic function and metabolism. II. Bacterial metabolites in feces and urine. Am J Clin Nutr 1979;32:2094-101.

34 Heaton KW. Diet and diverticulosis-new leads. Gut 1985;26:541-3.

35 Kang JY, Firwana B, Green AE, Matthews H, Poullis A, Barnabas A, et al. Uncomplicated diverticular disease is not a common cause of colonic symptoms. Aliment Pharmacol Ther 2011;33:487-94.

36 Hoare J, Henderson L, Bates CJ, Prentice A, Birch M, Swan G, et al. The national diet and nutrition survey: adults aged 19 to 64 years. Stationery Office, 2004.

Accepted: 22 May 2011

Cite this as: BMJ 2011;343:d4131 


\section{Tables}

Table 1| Baseline characteristics of EPIC-Oxford participants for men and women by diet group. Figures are numbers (percentage) of participants unless stated otherwise

\begin{tabular}{|c|c|c|c|c|}
\hline & \multicolumn{2}{|c|}{ Men } & \multicolumn{2}{|c|}{ Women } \\
\hline & Non-vegetarian $(n=7400)$ & Vegetarian $(n=3940)$ & Non-vegetarian ( $n=24$ 174) & Vegetarian $(n=11$ 519) \\
\hline \multicolumn{5}{|l|}{ Age at recruitment (years): } \\
\hline $20-29$ & $456(6.2)$ & $614(15.6)$ & $2467(10.2)$ & $3218(27.9)$ \\
\hline $30-39$ & $1167(15.8)$ & $1324(33.6)$ & $4727(19.6)$ & $3673(31.9)$ \\
\hline $40-49$ & $1900(25.7)$ & $1029(26.1)$ & $6557(27.1)$ & $2480(21.5)$ \\
\hline $50-59$ & $1730(23.4)$ & $488(12.4)$ & $5945(24.6)$ & $1237(10.7)$ \\
\hline $60-69$ & $1504(20.3)$ & $243(6.2)$ & $3279(13.6)$ & $528(4.6)$ \\
\hline $70-79$ & $541(7.3)$ & $167(4.2)$ & $1038(4.3)$ & $267(2.3)$ \\
\hline $80-89$ & $102(1.4)$ & $75(1.9)$ & $161(0.7)$ & $116(1.0)$ \\
\hline Median age (years) & 50 & 40 & 47 & 36 \\
\hline \multicolumn{5}{|l|}{ Smoking status: } \\
\hline Never & $3662(49.5)$ & $2327(59.1)$ & $14752(61.0)$ & $7503(65.1)$ \\
\hline Former & $2660(35.9)$ & $1169(29.7)$ & $6704(27.7)$ & $2887(25.1)$ \\
\hline $\begin{array}{l}\text { Light smoker }(<15 \\
\text { cigarettes/day) }\end{array}$ & $700(9.5)$ & $293(7.4)$ & $1554(6.4)$ & $784(6.8)$ \\
\hline $\begin{array}{l}\text { Heavy smoker ( } \geq 15 \\
\text { cigarettes/day) }\end{array}$ & $378(5.1)$ & $151(3.8)$ & $1164(4.8)$ & $345(3.0)$ \\
\hline \multicolumn{5}{|l|}{ Alcohol consumption (g/d): } \\
\hline$<1$ & $730(9.9)$ & $753(19.1)$ & $4086(16.9)$ & $2494(21.7)$ \\
\hline $1-7$ & $2275(30.7)$ & $1228(31.2)$ & $11160(46.2)$ & $5021(43.6)$ \\
\hline $8-15$ & $1926(26.0)$ & $914(23.2)$ & $5836(24.1)$ & $2629(22.8)$ \\
\hline$\geq 16$ & $2469(33.4)$ & $1045(26.5)$ & $3092(12.8)$ & $1375(11.9)$ \\
\hline $\begin{array}{l}\text { Median alcohol consumption } \\
\text { (g/day) }\end{array}$ & 10.5 & 7.7 & 5.3 & 4.9 \\
\hline \multicolumn{5}{|l|}{ Body mass index (BMI): } \\
\hline$<20$ & $321(4.5)$ & $416(11.0)$ & $2628(11.2)$ & 2199 (19.9) \\
\hline $20.0-22.4$ & $1545(21.6)$ & $1234(32.7)$ & $7221(30.8)$ & $4152(37.5)$ \\
\hline $22.5-24.9$ & $2430(34.0)$ & $1201(31.8)$ & $6411(27.4)$ & $2693(24.3)$ \\
\hline $25.0-27.4$ & $1695(23.7)$ & $601(15.9)$ & $3652(15.6)$ & $1119(10.1)$ \\
\hline$\geq 27.5$ & $1163(16.3)$ & $324(8.6)$ & $3528(15.1)$ & $901(8.1)$ \\
\hline Median BMI & 24.3 & 22.9 & 23.1 & 22.0 \\
\hline \multicolumn{5}{|l|}{ Physical activity: } \\
\hline Inactive & $1725(25.6)$ & $726(20.0)$ & $5071(25.4)$ & $2161(21.1)$ \\
\hline Active & $5026(74.4)$ & $2899(80.0)$ & $14923(74.6)$ & 8079 (78.9) \\
\hline \multicolumn{5}{|l|}{ Education: } \\
\hline Some secondary school & $2304(33.8)$ & $1019(27.3)$ & $9637(43.5)$ & $3547(32.4)$ \\
\hline Higher secondary school & $1487(21.8)$ & $864(23.1)$ & $5400(24.4)$ & $2933(26.8)$ \\
\hline University degree or equivalent & $3021(44.3)$ & $1854(49.6)$ & $7128(32.2)$ & $4461(40.8)$ \\
\hline \multicolumn{5}{|l|}{ Townsend deprivation index: } \\
\hline$<-3.3$ (richest) & $1821(27.9)$ & $712(20.6)$ & $5342(25.9)$ & $2183(21.7)$ \\
\hline$-3.3-<-1.8$ & $1707(26.2)$ & $774(22.4)$ & $5378(26.0)$ & $2367(23.5)$ \\
\hline$-1.8-<0.3$ & $1572(24.1)$ & $869(25.2)$ & $5105(24.7)$ & $2493(24.8)$ \\
\hline$\geq 0.3$ (poorest) & $1426(21.9)$ & $1100(31.8)$ & $4839(23.4)$ & $3008(29.9)$ \\
\hline Self reported diabetes & $189(2.7)$ & $49(1.3)$ & $322(1.5)$ & $60(0.5)$ \\
\hline Self reported hypertension ${ }^{*}$ & $1017(14.2)$ & $265(6.9)$ & $2892(13.4)$ & $716(6.5)$ \\
\hline Self reported hyperlipidaemia ${ }^{*}$ & $772(10.9)$ & $119(3.2)$ & $1403(6.6)$ & $245(2.3)$ \\
\hline
\end{tabular}


Table 1 (continued)

\begin{tabular}{|c|c|c|c|c|}
\hline & \multicolumn{2}{|c|}{ Men } & \multicolumn{2}{|c|}{ Women } \\
\hline & Non-vegetarian $(n=7400)$ & Vegetarian $(n=3940)$ & Non-vegetarian $(n=24174)$ & Vegetarian $(n=11519)$ \\
\hline Long term medical treatment ${ }^{*}$ & $2057(28.2)$ & $702(17.9)$ & $6024(27.3)$ & $2181(19.2)$ \\
\hline Use of oral contraceptives* & - & - & $17451(72.9)$ & 8971 (78.3) \\
\hline Use of $\mathrm{HRT}^{*}$ & - & - & $5316(22.3)$ & $868(7.7)$ \\
\hline
\end{tabular}

HRT=hormone replacement therapy.

*Unknown for some men and women, respectively: self reported diabetes, $n=447$ and 3563; self reported hypertension, $n=358$ and 3058 ; self reported hyperlipidaemia, $\mathrm{n}=466$ and 3510 ; receiving long term medical treatment, $\mathrm{n}=126$ and 2221 ; use of oral contraceptives, $\mathrm{n}=302$ (women only); use of HRT, $\mathrm{n}=494$ (women only). 
Table 2| Dietary characteristics at baseline in EPIC-Oxford participants for men and women by diet group at baseline and follow-up. Figures are numbers (percentage) of participants unless stated otherwise

\begin{tabular}{|c|c|c|c|c|}
\hline & \multicolumn{2}{|c|}{ Men } & \multicolumn{2}{|c|}{ Women } \\
\hline & Non-vegetarian $(n=7400)$ & Vegetarian $(n=3940)$ & Non-vegetarian $(n=24$ 174) & Vegetarian $(n=11519)$ \\
\hline \multicolumn{5}{|c|}{ Time on vegetarian diet (years): } \\
\hline$\leq 5$ or unknown & - & $1298(32.9)$ & - & $3946(34.3)$ \\
\hline$>5$ & - & $2642(67.1)$ & - & $7573(65.7)$ \\
\hline \multicolumn{5}{|l|}{ Diet group at follow-up*: } \\
\hline Non-vegetarian & $5000(97.3)$ & $254(10.4)$ & $16254(97.6)$ & $1169(16.0)$ \\
\hline Vegetarian & $139(2.7)$ & $2194(89.6)$ & $408(2.4)$ & $6129(84.0)$ \\
\hline \multicolumn{5}{|c|}{ Median (IQR) intake of selected foods and nutrients: } \\
\hline Meat (g/day) & $66(24-106)$ & - & $53(11-92)$ & - \\
\hline Fish (g/day) & $34(23-51)$ & - & $34(21-52)$ & - \\
\hline Dairy milk (mL/day) & $293(146-439)$ & $146(0-439)$ & $293(146-439)$ & $146(50-293)$ \\
\hline Dairy cheese (g/day) & $15(5-27)$ & $19(5-35)$ & $19(9-31)$ & $23(11-38)$ \\
\hline Vegetables (g/day) & 207 (148-284) & 246 (177-339) & $240(173-325)$ & 267 (191-370) \\
\hline Fresh fruit (g/day) & $180(102-292)$ & $200(115-332)$ & $235(144-361)$ & $240(140-379)$ \\
\hline Englyst fibre (g/day) & $18(14-23)$ & $22(17-27)$ & $18(14-23)$ & $21(16-26)$ \\
\hline
\end{tabular}




\begin{tabular}{|c|c|c|c|}
\hline & Cases & Relative risk $(95 \% \mathrm{Cl})^{*}$ & $P$ value \\
\hline \multicolumn{4}{|l|}{ Smoking: } \\
\hline Never & 396 & 1.00 & \multirow[t]{4}{*}{$<0.001 \dagger$} \\
\hline Former & 324 & $1.31(1.13$ to 1.53$)$ & \\
\hline Light smoker & 46 & 1.34 (0.98 to 1.82$)$ & \\
\hline Heavy smoker & 46 & 1.86 (1.36 to 2.54$)$ & \\
\hline \multicolumn{4}{|l|}{ Alcohol consumption (g/day): } \\
\hline$<1$ & 181 & 0.94 (0.79 to 1.13$)$ & \multirow[t]{4}{*}{0.267} \\
\hline $1-7$ & 363 & 1.00 & \\
\hline $8-15$ & 161 & $0.86(0.71$ to 1.04$)$ & \\
\hline$\geq 16$ & 107 & $0.83(0.67$ to 1.04$)$ & \\
\hline \multicolumn{4}{|l|}{ BMI $\left(\mathrm{kg} / \mathrm{m}^{2}\right):$} \\
\hline$<20.0$ & 30 & $0.63(0.42$ to 0.93$)$ & \multirow[t]{5}{*}{$<0.001$} \\
\hline $20.0-22.5$ & 151 & 1.00 & \\
\hline $22.5-25.0$ & 231 & $1.23(1.00$ to 1.51$)$ & \\
\hline $25.0-27.5$ & 189 & 1.54 (1.24 to 1.92$)$ & \\
\hline$\geq 27.5$ & 181 & 1.67 (1.34 to 2.08$)$ & \\
\hline \multicolumn{4}{|l|}{ Education level attained: } \\
\hline Some secondary school & 412 & 1.00 & \multirow[t]{3}{*}{0.001} \\
\hline Higher secondary school & 129 & 0.72 (0.59 to 0.88$)$ & \\
\hline University degree or equivalent & 155 & $0.78(0.64$ to 0.95$)$ & \\
\hline \multicolumn{4}{|l|}{ Townsend deprivation index: } \\
\hline$<-3.3$ (richest) & 173 & 1.00 & \multirow[t]{4}{*}{0.013} \\
\hline$-3.3-<-1.8$ & 173 & 0.99 (0.80 to 1.22$)$ & \\
\hline$-1.8-<0.3$ & 181 & 1.21 (0.98 to 1.49$)$ & \\
\hline$\geq 0.3$ (poorest) & 169 & 1.34 (1.08 to 1.66$)$ & \\
\hline \multicolumn{4}{|l|}{ Physical activity: } \\
\hline Inactive & 262 & 1.00 & \multirow[t]{2}{*}{0.086} \\
\hline Active & 392 & 0.87 (0.74 to 1.02$)$ & \\
\hline \multicolumn{4}{|l|}{ Self reported diabetes: } \\
\hline No & 661 & 1.00 & \multirow[t]{2}{*}{0.366} \\
\hline Yes & 21 & $1.23(0.79$ to 1.91$)$ & \\
\hline \multicolumn{4}{|l|}{ Self reported hypertension: } \\
\hline No & 517 & 1.00 & \multirow[t]{2}{*}{$<0.001$} \\
\hline Yes & 194 & $1.44(1.21$ to 1.70$)$ & \\
\hline \multicolumn{4}{|l|}{ Self reported hyperlipidaemia: } \\
\hline No & 575 & 1.00 & \multirow[t]{2}{*}{$<0.001$} \\
\hline Yes & 116 & $1.47(1.19$ to 1.80$)$ & \\
\hline \multicolumn{4}{|l|}{ Long term medical treatment: } \\
\hline No & 372 & 1.00 & \multirow[t]{2}{*}{$<0.001$} \\
\hline Yes & 344 & 1.59 (1.37 to 1.85$)$ & \\
\hline \multicolumn{4}{|l|}{ Ever used oral contraceptives: } \\
\hline No & 276 & 1.00 & \multirow[t]{2}{*}{0.004} \\
\hline Yes & 323 & 1.31 (1.09 to 1.58$)$ & \\
\hline \multicolumn{4}{|l|}{ Ever used HRT: } \\
\hline No & 373 & 1.00 & \multirow[t]{2}{*}{0.004} \\
\hline Yes & 229 & 1.29 (1.09 to 1.54$)$ & \\
\hline
\end{tabular}

$\mathrm{BMI}=$ body mass index; HRT=hormone replacement therapy.

*Stratified by sex, method of recruitment, and region of residence and adjusted for smoking where appropriate. 
Table 3 (continued) 


\begin{tabular}{|c|c|c|c|c|c|}
\hline & \multirow[b]{2}{*}{ Cases } & \multicolumn{2}{|c|}{ Unadjusted* } & \multicolumn{2}{|c|}{ Adjusted $†$} \\
\hline & & Relative risk $(95 \% \mathrm{Cl})$ & $P$ value & Relative risk $(95 \% \mathrm{Cl})$ & $P$ value \\
\hline \multicolumn{6}{|l|}{ Vegetarian status: } \\
\hline No & 710 & 1.00 & \multirow[t]{2}{*}{$<0.001 \ddagger$} & 1.00 & \multirow[t]{2}{*}{$0.001 \neq$} \\
\hline Yes & 102 & $0.62(0.50$ to 0.77$)$ & & $0.70(0.56$ to 0.87$)$ & \\
\hline \multicolumn{6}{|l|}{ Diet group: } \\
\hline Meat eater & 633 & 1.00 & \multirow[t]{3}{*}{$<0.001$} & 1.00 & \multirow[t]{3}{*}{0.003} \\
\hline No meat but some fish & 77 & 0.83 (0.65 to 1.06$)$ & & 0.91 (0.71 to 1.16$)$ & \\
\hline Vegetarian or vegan & 102 & 0.60 (0.48 to 0.75$)$ & & 0.69 (0.55 to 0.86$)$ & \\
\hline \multicolumn{6}{|l|}{ Diet group: } \\
\hline Meat eater & 633 & 1.00 & \multirow[t]{4}{*}{$<0.001$} & 1.00 & \multirow[t]{4}{*}{0.001} \\
\hline No meat but some fish & 77 & 0.83 (0.65 to 1.06$)$ & & $0.90(0.71$ to 1.16$)$ & \\
\hline Vegetarian & 98 & $0.65(0.52$ to 0.81$)$ & & 0.73 (0.58 to 0.92$)$ & \\
\hline Vegan & 4 & $0.22(0.08$ to 0.59$)$ & & $0.28(0.10$ to 0.74$)$ & \\
\hline
\end{tabular}

*Stratified by sex, method of recruitment, and region of residence.

†Stratified by sex, method of recruitment, and region of residence and adjusted for smoking, education level, Townsend deprivation index, self reported hyperlipidaemia, receiving long term medical treatment, ever used oral contraceptives, ever used hormone replacement therapy, and BMI (fully adjusted model).

$\mp \chi^{2}$ test. 


\begin{tabular}{|c|c|c|c|c|c|}
\hline & \multirow[b]{2}{*}{ Cases } & \multicolumn{2}{|c|}{ Unadjusted $^{*}$} & \multicolumn{2}{|c|}{ Adjustedt } \\
\hline & & Relative risk (95\% Cl) & $P$ value & Relative risk (95\% Cl) & $P$ value \\
\hline \multicolumn{6}{|l|}{ Meat intake (g/day): } \\
\hline$\geq 100$ & 204 & 1.00 & \multirow[t]{5}{*}{$0.002 \ddagger$} & 1.00 & \multirow[t]{5}{*}{$0.020 \ddagger$} \\
\hline $50-99$ & 272 & $0.94(0.78$ to 1.13$)$ & & $0.98(0.81$ to 1.18$)$ & \\
\hline$<50$ & 157 & 0.84 (0.68 to 1.04$)$ & & $0.95(0.76$ to 1.18$)$ & \\
\hline No meat but some fish & 77 & 0.77 (0.58 to 1.01$)$ & & 0.88 (0.67 to 1.17$)$ & \\
\hline Vegetarian or vegan & 102 & $0.55(0.43$ to 0.71$)$ & & $0.67(0.52$ to 0.87$)$ & \\
\hline \multicolumn{6}{|c|}{ Englyst fibre intake (g/day)§ף: } \\
\hline 1 (lowest fifth) & 184 & 1.00 & \multirow[t]{5}{*}{$<0.001^{* *}$} & 1.00 & \multirow[t]{5}{*}{$<0.001^{\star *}$} \\
\hline 2 & 177 & $0.84(0.69$ to 1.04$)$ & & $0.86(0.69$ to 1.06$)$ & \\
\hline 3 & 164 & 0.75 (0.61 to 0.93$)$ & & 0.76 (0.61 to 0.96$)$ & \\
\hline 4 & 160 & 0.72 (0.58 to 0.89$)$ & & $0.72(0.57$ to 0.92$)$ & \\
\hline 5 (highest fifth) & 127 & $0.58(0.46$ to 0.73$)$ & & $0.59(0.46$ to 0.78$)$ & \\
\hline
\end{tabular}

*Stratified by sex, method of recruitment, and region of residence.

†Stratified by sex, method of recruitment, and region of residence and adjusted for smoking, education level, Townsend deprivation index, self reported hyperlipidaemia, receiving long term medical treatment, ever used oral contraceptives, ever used hormone replacement therapy, and BMI (fully adjusted model).

$\ddagger \chi^{2}$ test.

§Cut-off points: $14.0,17.5,21.2$, and $26.1 \mathrm{~g} /$ day for men; 14.0, 17.5, 20.9, and $25.5 \mathrm{~g} /$ day for women.

IFurther adjusted for sex specific fifths of total energy intake.

${ }^{* \star} P$ for trend obtained by replacing fifths of dietary fibre with continuous variable equal to sex specific median in each fifth. 


\begin{tabular}{|c|c|c|c|c|c|c|c|c|c|}
\hline \multicolumn{10}{|c|}{ Table 6| Association between diet group and intake of dietary fibre and risk of diverticular disease stratified by sex } \\
\hline & \multicolumn{3}{|c|}{ All participants } & \multicolumn{3}{|c|}{ Men } & \multicolumn{3}{|c|}{ Women } \\
\hline & Cases & $\begin{array}{l}\text { Relative risk } \\
(95 \% \mathrm{Cl})^{*}\end{array}$ & $P$ value & Cases & $\begin{array}{c}\text { Relative risk } \\
(95 \% \mathrm{Cl})^{\star}\end{array}$ & $P$ value & Cases & $\begin{array}{c}\text { Relative risk } \\
(95 \% \mathrm{Cl})^{\star}\end{array}$ & $P$ value \\
\hline \multicolumn{10}{|c|}{ Diet group $(P=0.699$ for interactiont $)$ : } \\
\hline Meat eater & 633 & 1.00 & \multirow[t]{3}{*}{$0.003 \ddagger$} & 155 & 1.00 & \multirow[t]{3}{*}{$0.125 \ddagger$} & 478 & 1.00 & \multirow[t]{3}{*}{$0.025 \ddagger$} \\
\hline Fish eater & 77 & $\begin{array}{c}0.91 \text { ( } 0.71 \text { to } \\
1.16)\end{array}$ & & 17 & $\begin{array}{c}1.04(0.61 \text { to } \\
1.75)\end{array}$ & & 60 & $\begin{array}{c}0.88 \text { (0.66 to } \\
1.16)\end{array}$ & \\
\hline $\begin{array}{l}\text { Vegetarian } \\
\text { or vegan }\end{array}$ & 102 & $\begin{array}{c}0.69(0.55 \text { to } \\
0.86)\end{array}$ & & 26 & $\begin{array}{c}0.65 \text { (0.41 to } \\
1.02)\end{array}$ & & 76 & $\begin{array}{c}0.71 \text { ( } 0.55 \text { to } \\
0.92)\end{array}$ & \\
\hline \multicolumn{10}{|c|}{ Englyst fibre intake ( $\mathrm{g} / \mathrm{day})(\mathrm{P}=0.223$ for interaction +$)$ : } \\
\hline $\begin{array}{l}1 \text { (lowest } \\
\text { fifth) }\end{array}$ & 184 & 1.00 & \multirow[t]{5}{*}{$<0.0019$} & 42 & 1.00 & \multirow[t]{5}{*}{$0.263 \rrbracket$} & 142 & 1.00 & \multirow[t]{5}{*}{$<0.001 \rrbracket$} \\
\hline 2 & 177 & $\begin{array}{c}0.86 \text { (0.69 to } \\
1.06)\end{array}$ & & 48 & $\begin{array}{c}1.04(0.67 \text { to } \\
1.60)\end{array}$ & & 129 & $\begin{array}{c}0.82(0.64 \text { to } \\
1.04)\end{array}$ & \\
\hline 3 & 164 & $\begin{array}{c}0.76 \text { (0.61 to } \\
0.96)\end{array}$ & & 32 & $\begin{array}{c}0.63 \text { (0.38 to } \\
1.04)\end{array}$ & & 132 & $\begin{array}{c}0.81 \text { (0.63 to } \\
1.04)\end{array}$ & \\
\hline 4 & 160 & $\begin{array}{c}0.72(0.57 \text { to } \\
0.92)\end{array}$ & & 42 & $\begin{array}{c}0.83(0.51 \text { to } \\
1.34) \\
\end{array}$ & & 118 & $\begin{array}{c}0.70(0.53 \text { to } \\
0.92)\end{array}$ & \\
\hline $\begin{array}{l}5 \text { (highest } \\
\text { fifth) }\end{array}$ & 127 & $\begin{array}{c}0.59 \text { ( } 0.46 \text { to } \\
0.78)\end{array}$ & & 34 & $\begin{array}{c}0.77(0.45 \text { to } \\
1.31)\end{array}$ & & 93 & $\begin{array}{c}0.56(0.41 \text { to } \\
0.76)\end{array}$ & \\
\hline
\end{tabular}

*Stratified by sex, method of recruitment, and region of residence and adjusted for smoking, education level, Townsend deprivation index, hyperlipidaemia, receiving long term medical treatment, ever used oral contraceptives, ever used hormone replacement therapy, and BMI, where appropriate and using separate models for each subset.

†Tests of interaction performed with data for all participants by adding diet group or fifths of dietary fibre intake $\times$ sex interaction to model as appropriate. $\ddagger \mathrm{x}^{2}$ test.

§Further adjusted for sex specific fifths of energy intake.

IP for trend obtained by replacing fifths of dietary fibre by continuous variable equal to sex specific median in each fifth. 


\begin{tabular}{|c|c|c|c|c|c|c|c|c|c|}
\hline & \multicolumn{3}{|c|}{ All participants } & \multicolumn{3}{|c|}{ Aged $<60$} & \multicolumn{3}{|c|}{ Aged $\geq 60$} \\
\hline & Cases & $\begin{array}{c}\text { Relative risk } \\
(95 \% \mathrm{Cl})^{*}\end{array}$ & $P$ value & Cases & $\begin{array}{c}\text { Relative risk } \\
(95 \% \mathrm{Cl})^{*}\end{array}$ & $P$ value & Cases & $\begin{array}{c}\text { Relative risk } \\
(95 \% \mathrm{Cl})^{*}\end{array}$ & $P$ value \\
\hline \multicolumn{10}{|c|}{ Diet group $(P=0.069$ for interaction +$)$ : } \\
\hline Meat eater & 633 & 1.00 & \multirow[t]{3}{*}{$0.003 \ddagger$} & 291 & 1.00 & \multirow[t]{3}{*}{$0.286 \ddagger$} & 342 & 1.00 & \multirow[t]{3}{*}{$0.001 \neq$} \\
\hline Fish eater & 77 & $\begin{array}{c}0.91 \text { ( } 0.71 \text { to } \\
1.16)\end{array}$ & & 35 & $\begin{array}{c}0.81 \text { (0.56 to } \\
1.17)\end{array}$ & & 42 & $\begin{array}{c}1.02(0.73 \text { to } \\
1.42)\end{array}$ & \\
\hline $\begin{array}{l}\text { Vegetarian } \\
\text { or vegan }\end{array}$ & 102 & $\begin{array}{c}0.69(0.55 \text { to } \\
0.86)\end{array}$ & & 67 & $\begin{array}{c}0.82(0.61 \text { to } \\
1.10)\end{array}$ & & 35 & $\begin{array}{c}0.53(0.37 \text { to } \\
0.76)\end{array}$ & \\
\hline \multicolumn{10}{|c|}{ Englyst fibre intake (g/day) $(\mathrm{P}=0.366$ for interaction +$)$ : } \\
\hline $\begin{array}{l}1 \text { (lowest } \\
\text { fifth) }\end{array}$ & 184 & 1.00 & \multirow[t]{5}{*}{$<0.0019$} & 105 & 1.00 & \multirow[t]{5}{*}{$0.004 \uparrow$} & 79 & 1.00 & \multirow[t]{5}{*}{$0.006 \uparrow$} \\
\hline 2 & 177 & $\begin{array}{c}0.86 \text { (0.69 to } \\
1.06)\end{array}$ & & 97 & $\begin{array}{c}0.97(0.73 \text { to } \\
1.29)\end{array}$ & & 80 & $\begin{array}{c}0.75 \text { (0.54 to } \\
1.04)\end{array}$ & \\
\hline 3 & 164 & $\begin{array}{c}0.76 \text { (0.61 to } \\
0.96)\end{array}$ & & 69 & $\begin{array}{c}0.71(0.52 \text { to } \\
0.98)\end{array}$ & & 95 & $\begin{array}{c}0.81(0.59 \text { to } \\
1.13)\end{array}$ & \\
\hline 4 & 160 & $\begin{array}{c}0.72(0.57 \text { to } \\
0.92)\end{array}$ & & 72 & $\begin{array}{c}0.80(0.57 \text { to } \\
1.11)\end{array}$ & & 88 & $\begin{array}{c}0.67 \text { (0.48 to } \\
0.94)\end{array}$ & \\
\hline $\begin{array}{l}5 \text { (highest } \\
\text { fifth) }\end{array}$ & 127 & $\begin{array}{c}0.59 \text { (0.46 to } \\
0.78)\end{array}$ & & 50 & $\begin{array}{c}0.59(0.40 \text { to } \\
0.87)\end{array}$ & & 77 & $\begin{array}{c}0.58(0.40 \text { to } \\
0.85)\end{array}$ & \\
\hline
\end{tabular}

*Stratified by sex, method of recruitment, and region of residence and adjusted for smoking, education level, Townsend deprivation index, hyperlipidaemia, receiving long term medical treatment, ever used oral contraceptives, ever used hormone replacement therapy, and BMI, where appropriate and using separate models for each subset.

†Tests of interaction performed with data for all participants by adding a diet group or fifths of dietary fibre intake $\times$ age group interaction to model as appropriate. $\ddagger \mathrm{x}^{2}$ test.

§Further adjusted for sex specific fifths of energy intake.

IP for trend obtained by replacing fifths of dietary fibre with a continuous variable equal to sex specific median in each fifth. 